\title{
Physical exercise in children with congenital heart disease
}

\section{Ricard Serra Grima*}

Department of Cardiology, Hospital de Sant Pau, Barcelona, Spain

The number of newborn children alive with congenital heart disease is about $8-9$ per thousand. $85 \%$ overcome the congenital heart disease, this is due to the advanced techniques in pediatric heart surgery. During the last 40 years they have been using Tetralogy of Fallot repair and right now these children can live a normal life in most of cases.

Sudden death is not freqüent, only about $0.1 \%$ per year and only $8 \%$ occur practicing physical exercise. That is the reason why it is so important to enhance exercise since it is a complementary measure in the follow up of a clinical treatment and helps in all types of social inclusion [1].

Other benefits of practicing a sport in all ages is the improvement of cognitive function, memorization and learning process.

In order to achive these benefits we need two special basic conditions. First of all supervision of the exercise program in the first periods of time and also keeping regularity. If these two conditions are followed then the program will be modified acccording to tolerance and adaptation to the intensity of the work. The method should be as strict as the one used in high competition athletes.

In a study realized to children who had congentital heart disease surgery we have observed two problems. Most of these children commute from different towns and had to follow the post surgery control.

During the periods of hospitalizacion and post surgery the children were helped with physiotherapy until they got out of the hospital. The follow up of physiotherapy sometimes cannot be done in perfect conditions and the physical conditioning will be delayed. The second problem is that often these children are left out activities of children of their same age. Sometimes is the overprotection of their parents and even from Physical Education teachers.

Copyright: (C2020 Grima RS. This is an open-access article distributed under the terms of the Creative Commons Attribution License, which permits unrestricted use, distribution, and reproduction in any medium, provided the original author and source are credited.
Our point of view is that in order to solve these problems we recommend a follow up of active physiotherapy and training supervised by a professional expert.

An additional recommentation is to realize a Cardiopulmonary stress testing study in order to evaluate physical capacity and follow guidelines about type and intensity of the exercise. The aim is to improve performance and decrease the cardiovascular risc. This procedure has a positive effect and gives them more security [2].

We have observed that $70 \%$ of children practice exercise below their capacity. With this method and clinical follow up will avoid the exclusion and will improve their cognitive function. Lack of exercise is one of the factors that causes owerweight. The below average of physical fitness is consequence of physical inactivity and overweight.

In conclusion, the programs of physical exercise will help these children to participate in the activities of children of their own age.

The effects of the exercise improves physical capacity, quality of the life and cognitive function. All of these factors will help children with congenital heart surgery to have the same oportunities as all the others children with normal limitations.

\section{References}

1. Lynge TH, Jeppesen AG, Winkel BG, Glinge C, Schmidt MR (2018) Nationwide study Sudden cardiac death in People with Congenital Heart Defects Aged 0 to 35 years. Circ Arrhythm Electrophysiol 11: e005757. [Crossref]

2. Serra-Grima R, Doñate M, Borrás X, Rissech M, Puig T, et al. (2011) Cardiopulmonary stress testing in children who have had congenital heart disease surgery. Physical exercise recommendations during school hours. Rev Esp Cardiol 64: 780-787. [Crossref]
${ }^{*}$ Correspondence to: Ricard Serra Grima, Department of Cardiology, Hospital de Sant Pau, Barcelona, Spain, E-mail: JSerra@santpau.cat

Received: August 10, 2020; Accepted: August 17, 2020; Published: August 21, 2020 